Ueb. d. ägypt. Opuntia. - Ueb. d. Ranzigwerden der Butter. 145

\title{
Ueber die ägyptische Opuntia.
}

\author{
Von Dr. O. Popp.
}

Opuntia vulgaris ist in Aegypten, besonders in den Umgebungen von Cairo, sehr verbreitet, und findet sich ganz besonders an den Wohnungen der Fellah's, welche oft wie eine Hecke damit umgeben sind. Sie erreicht hier oft sehr bedeutende Dimensionen und gewährt dem Europäer einen ganz überraschenden Anblick. Die breiten, platten, blattartigen Stengel machen sich besonders schön, wenn sie ihre purpurfarbenen Früchte tragen.

Die Früchte der Opuntia, die Cactusfeigen, sind an Form den Smyrnaer Feigen ähnlich und besitzen im Znstande der Reife einen äusserst angenehmen, erfrischenden Geschmack. Sie enthalten in einem saftigen, rothen Muss zahlreiche kleine Samen; die Fruchthülle ist mit unzähligen feinen Haaren besetzt, welche auf der Haut ein empfindliches Stechen erzeugen. Das Mark der Früchte enthält neben etwas Rohrzucker besonders Traubenzucker, und einen äusserst tingirenden rothen Farbstoff, der dem der Cochenille sehr ähnlich ist, nur mehr ins Violette sich neigt; er soll in früheren Zeiten auch als Färbesubstanz angewandt worden sein. Die Cactusfeigen werden von den Arabern sehr geschätzt und gehen nnter dem Namen: Feigen der Barbarei.

Laboratorium Göttingen, Mai 1870.

\section{Ueber das Ranzigwerden der Butter.}

Von Dr. E. Pfeiffer aus Jena. *)

Bei Versuchen über die fetten Säuren der ranzigen Butter fand ich, dass im Sitze der stärksten Rancidität, an der Oberfläche (einer durch dunklere Färbung gekennzeichneten Schicht) sich ein dichtes Netz von Pilzen ausbreitet, welches durch Behandlung mit Aether unangetastet hinter-

*) Briefliche Mittheilung an H. L.

Aroh. d. Pharm. CXCIII. Bds, 2. Hft. 
bleibt und wohl meist für geronnenes Caseïn und dgl. genommen worden ist. Ich erkannte sogleich darin die Auskeimungen (Schizomycelium) der verbreitetsten Schimmelpilze, Aspergillus und Penicillium, in allen ihren Uebergängen bis zur fertigen Hefenzelle der Alkoholgährung und halte mich hierdurch, sowie durch den sonstigen Charakter des scharfen Geruchsprincips der ranzigen Butter für berechtigt, anzunehmen, dass eine alkoholische Gährung und Bildung höherer Aether einen Theil dieser übrigens sehr gemischten Gährung ausmacht. Die in die Milch hineinfallenden Sporen verursachen das Gerinnen derselben. Durch das Aufkochen werden diese Sporen unwirksam und es bildet sich zugleich ein schützendes Caseïnhäutchen an der Oberfläche der Milch. Das leichtere Gerinnen während eines Gewitters erkläre ich durch die höhere Temperatur während desselben; wir wissen für die Kartoffeln, dass durch einen einzigen warmen Regentag (bei Südwest) das Kraut schwarz wird, während es vorher bei herrschendem Nordost monatelang widerstanden hatte.

Die noch in der Butter vorhandenen Molkentröpfchen enthalten je nach der angewendeten grössern oder geringern Reinlichkeit weniger oder mehr Pilzsporen und werden zu einer Milchsäuregährung Veranlassung geben, die nach dem Verschwinden der Luft in Buttersäuregährung iubergehen wird und den nach einigen Tagen auftretenden veränderten Geschmack verursacht.

Hiermit ist für das Innere der Verderbnissprocess so ziemlich beendigt und es beginnt, unterstützt von der nachdringenden Luft, das Leben an der Oberfläche, in Form eines dichten Pilznetzes, welches den nun auftretenden scharfen Geruch, das Freiwerden höherer Fettsäuren und die theilweise Aetherbildung verursacht. Ich behalte mir vor, später auf diesen Gegenstand zurückzukommen. 